\title{
The Impact of Plants on the Reduction of Volatile Organic Compounds in a Small Space
}

\author{
Jeong-Eun Song ${ }^{1)}$, Yong-Shik Kim ${ }^{2)}$ and Jang-Yeul Sohn ${ }^{3)}$ \\ 1) Dept. of Sustainable Architectural Engineering, Graduate School, Hanyang University, Korea \\ 2) Division of Architectural Engineering, Incheon University, Korea \\ 3) Division of Architecture, College of Architecture, Hanyang University, Korea
}

\begin{abstract}
This study aims at examining the reduction of indoor air contaminants by plants placed in an indoor space. Field measurements were performed using Aglaonema brevispathum, Pachira aquatica, and Ficus benjamiana, which were verified as air-purifying plants by NASA. Three conditions for the amount of plants and positions were used in two separate rooms whose dimensions are identical. The concentration of Volatile Organic Compounds (VOCs) was monitored three hours after the plants were placed and three days after the plants were placed. The variations of concentration of Benzene, Toluene, Etylbenzene, and Xylene (BTEX), as well as Formaldehyde, which are all known as the major elements of Volatile Organic Compounds were monitored. The amount of reduction in concentration of Toluene and Formaldehyde was monitored 3 hours and 3 days after the plants were placed in the space. The reduction in the concentration of Benzene, Toluene, Etylbenzene, Xylene, and Formaldehyde was significantly greater when plants were present. When plants were placed near a window, the reduction of concentration was greater. The more plants were used, the more a reduction of indoor air contaminants occurred. The effect of reducing the concentration of air contaminants increased when the amount of plants increased, and when the plants were placed in sunny area. The concentration of Toluene was reduced by $45.6 \mu \mathrm{g} / \mathrm{m}^{3}$ when $10 \%$ of the model space was occupied by Aglaonema brevispathum. J Physiol Anthropol 26(6): 599-603, 2007 http://www.jstage.jst.go.jp/browse/jpa2
\end{abstract}

[DOI: 10.2114/jpa2.26.599]

Keywords: plant, indoor air quality, Volatile Organic Compounds (VOCs), Formaldehyde

\section{Introduction}

The interior of a piece of architecture is considered as a space shielded from the contamination of an outdoor setting. But indoor air is more contaminated than outdoor air as a result of construction materials, furniture, carpets, etc. To reduce indoor air pollution, air is ventilated by an airconditioner, and contaminants are controlled by many means. Of late, a biofiltering system using plants has been set up, where plants are utilized as a means of reducing indoor pollutants. This study explored the effect on reducing pollutants using three kinds of NASA's air purifying plants (Aglaonema brevispathum, Pachira aquatica, and Ficus benjamiana). The study administered an experiment differentiating the planting amount and the arrangement of three kinds of air purifying plants, and grasping the effect of reducing pollutants. According to recent research, most plants transpire through their stomata. During the process, they absorb indoor air pollution. Figure 1 shows air purification capacity.

\section{Methods}

This study produced a laboratory of width $3.5 \mathrm{~m}$, length $3.5 \mathrm{~m}$, height $2.4 \mathrm{~m}$ and measured indoor environmental factors. Plants were placed in one room, but they were not placed in the other room to make a comparative study. The two laboratories have the same size and use of a veneer board and coat of paint. There was no ventilation system. An experiment in a real apartment house is planned for the near future.

In order to compare the VOC levels, I started measuring them after confirming that there were the same conditions in the two laboratories at the beginning stage. I then put plants in one laboratory but none in the other. I observed the change of the subsequent VOC levels, measuring the presence of Benzene, Toluene, Etylbenzene, Xylene, and Formaldehyde.

A mini-pump with charcoal tube was used to sample VOCs for 60 minutes. After the sampling was completed, the sampled material was added to $\mathrm{CS}_{2}$ solution in order to extract VOCs. After the VOCs were extracted they were transferred to a GCFID (Gas Chromatography-Flame Ionization Detector). A DNPH-Cartridge was used to sample Formaldehyde for 30 minutes. After the sampling was completed, the sampled 


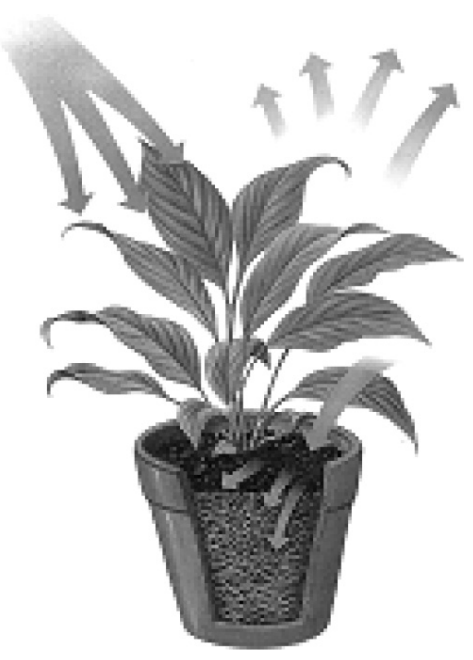

Fig. 1 Air purification capacity.

material was added to Acetonitrile solution. HPLC (High performance liquid chromatography) was used to analyze the concentration of Formaldehyde.

And grasped the reduced amount of concentration each time three kinds of plants are placed respectively.

There was no temperature and humidity difference and no ventilation fan was used. After each plant (Aglaonema brevispathum, Pachira aquatica and Ficus benjamiana) was introduced, the temperatures of the two laboratories were between 25.6 and $29.1^{\circ} \mathrm{C}$ and the outer temperature was between 23.2 and $27.2^{\circ} \mathrm{C}$. The temperature of the room was a little higher than that of the outside, and the temperature of the room in which plants were placed was a little lower than that of the room where there were no plants.

Figure 2 shows the ground plan of the laboratory, and Fig. 3 shows the number of plants and their placement. The monitoring setup is shown in Fig. 4.

\section{Results}

The study calculated the concentration of volatile Organic Compounds (VOCs) after plants were placed in $10 \%$ and $5 \%$ of the laboratory space.

Planting placement, experimented to sunny area and scattered area.

The effect on reduction of indoor air contaminants according to the amount of plants

1) Benzene was most effective when Pachira was planted. In particular, when Pachira was planted in $10 \%$ of the laboratory space, the reduction was $15.7 \mu \mathrm{g} / \mathrm{m}^{3}$. All three kinds of plants showed more reduction at $10 \%$ planting than $5 \%$. The variation of Benzene concentration is shown in Fig. 5.

2) Toluene was more effective when Aglaonema was planted at $10 \%$. Other plants showed a consdierably reduced amount of concentration at 10\%. 10\% of Aglaonema was reduced by $45.6 \mu \mathrm{g} / \mathrm{m}^{3}, 10 \%$ of Pachira by $31.0 \mu \mathrm{g} / \mathrm{m}^{3}, 10 \%$ of

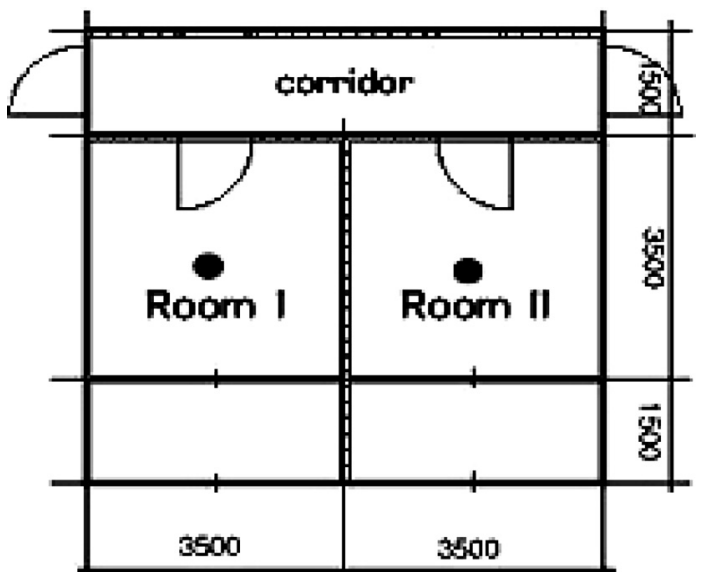

Fig. 2 Plan of the space.
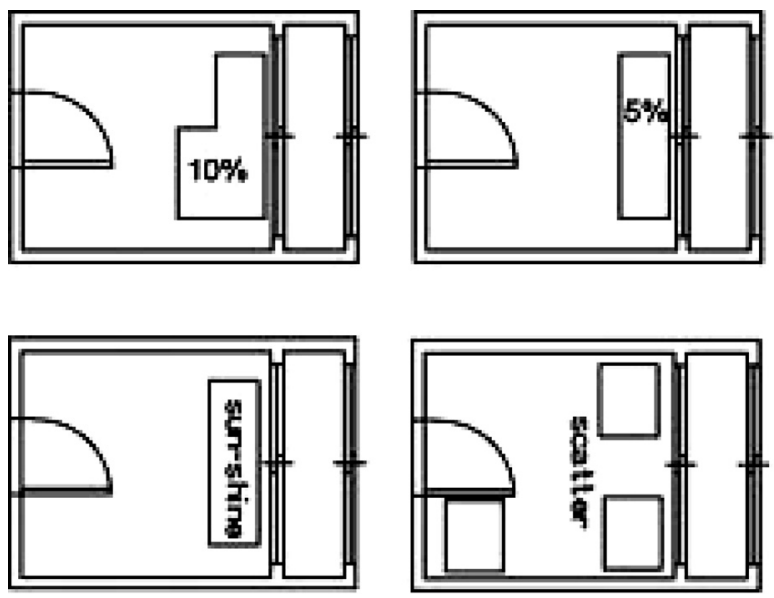

Fig. 3 Layout of plants.

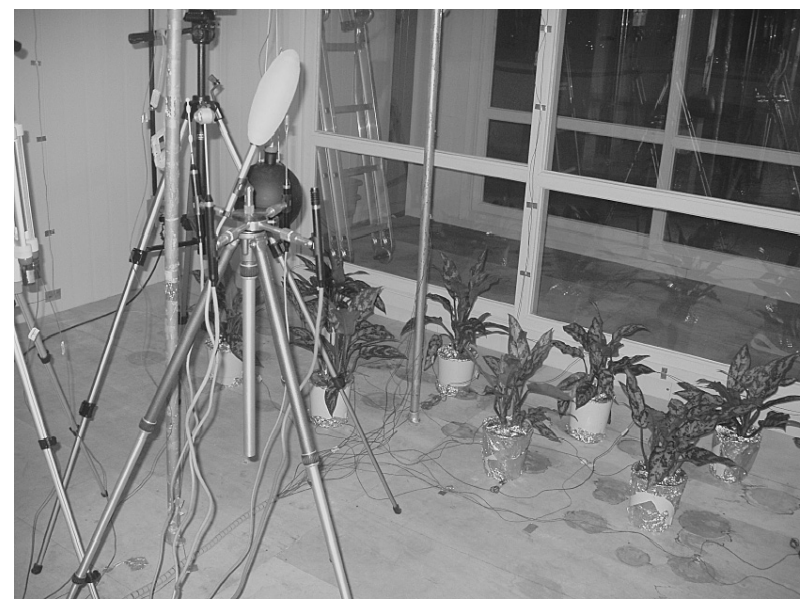

Fig. 4 The monitoring setup.

Ficus benjamiana by $36.1 \mu \mathrm{g} / \mathrm{m}^{3}$. The variation of Toluene concentration is shown in Fig. 6.

3) Etylbenzene was most effective when Pachira was planted. Planting pachira was reduced about two times Aglaonema, and three times Ficus benjamiana. 


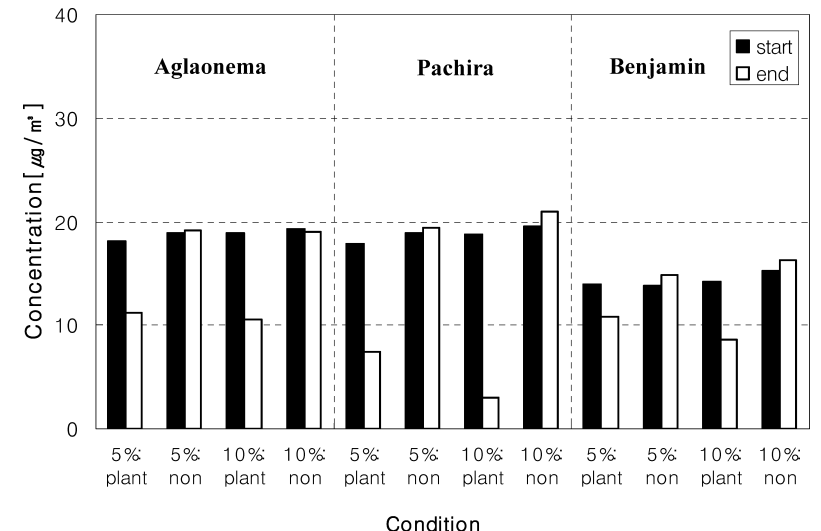

Fig. 5 Variation of Benzene concentration according to the amount of plant material present.

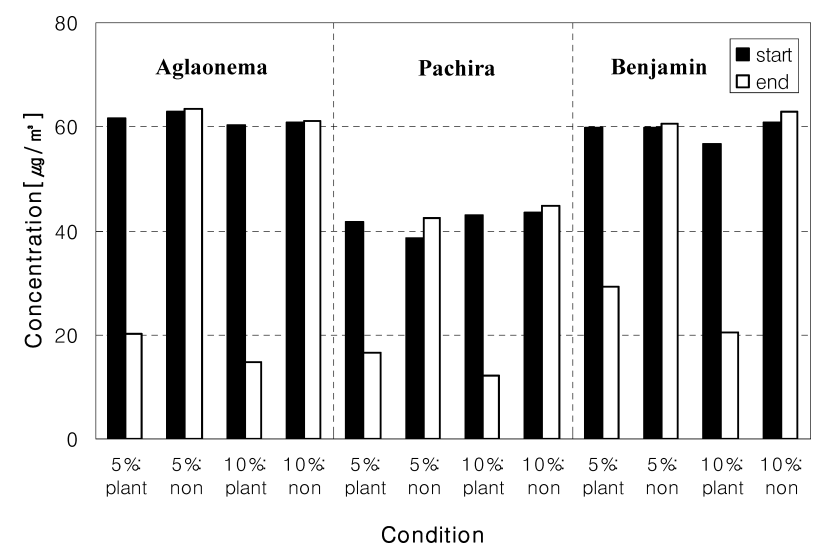

Fig. 6 Variation of Toluene concentration according to the amount of plant material present.

The variation of Etylbenzene concentration is shown in Fig. 7.

4) Xylene was effective when Aglaonema and pachira were planted. Both showed similar reduction amounts of $10.4-11.9 \mu \mathrm{g} / \mathrm{m}^{3}$.

The variation of Xylene concentration is shown in Fig. 8 .

5) Formaldehyde was most effective when $10 \%$ of Aglaonema was planted. Its reduced amount of condensation was $330.8 \mu \mathrm{g} / \mathrm{m}^{3}$. Among pollutants, the condensation of Formaldehyde was the highest, resulting in the most reduced amount. The variation of Formaldehyde concentration is shown in Fig. 9.

The effect of reducing contaminants according to the position of plants

1) Benzene was most reduced by $10.4 \mu \mathrm{g} / \mathrm{m}^{3}$ when Pachira was placed in a sunny area. In all plants, a sunny area was more effective than a shaded one. The variation of Benzene concentration is shown in Fig. 10.

2) Toluene was most effective when Aglaonema was placed in a sunny area. The reduced amount was $41.3 \mu \mathrm{g} / \mathrm{m}^{3}$, which is a value bigger than two times that of other plants. Toluene showed the reduced amount in the priority order of

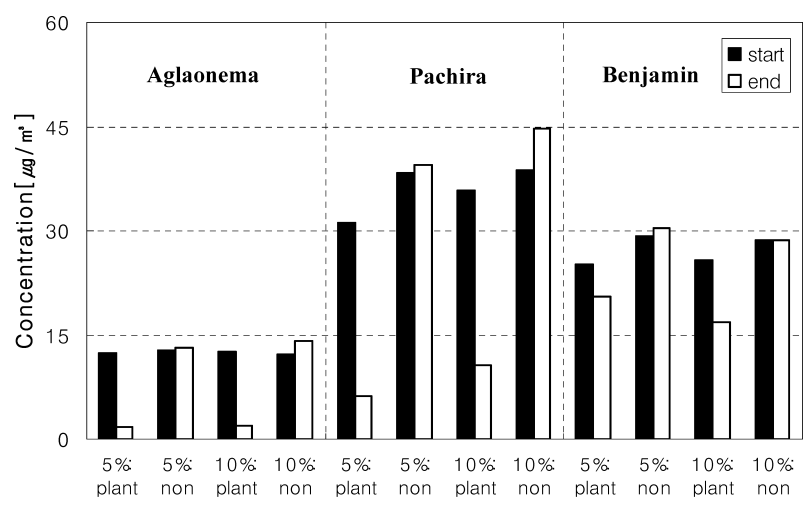

Condition

Fig. 7 Variation of Etylbenzene concentration according to the amount of plant material present.

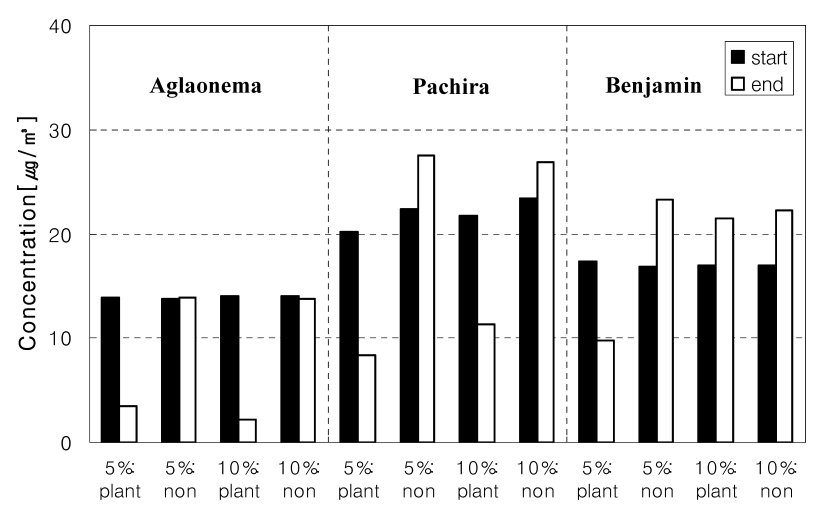

Condition

Fig. 8 Variation of Xylene concentration according to the amount of plant material present.

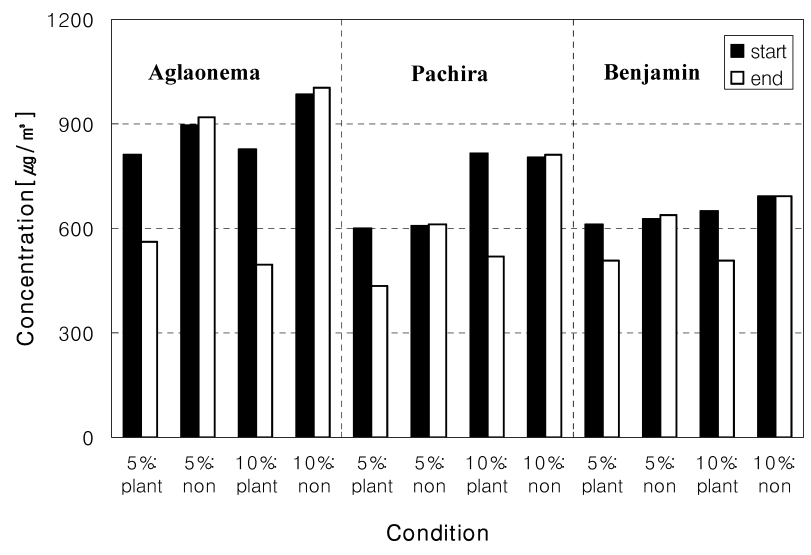

Fig. 9 Variation of $\mathrm{HCHO}$ concentration according to the amount of plant material present.

Aglaonema, Ficus benjamiana, Pachira. The variation of Toluene concentration is shown in Fig. 11.

3) Etylbenzene was most effective when Pachira was placed in a sunny area. The reduced amount of Etylbenzene was $3.5-25.0 \mu \mathrm{g} / \mathrm{m}^{3}$, which was reduced in all plants. The variation of Etylbenzene concentration is shown in Fig. 12. 


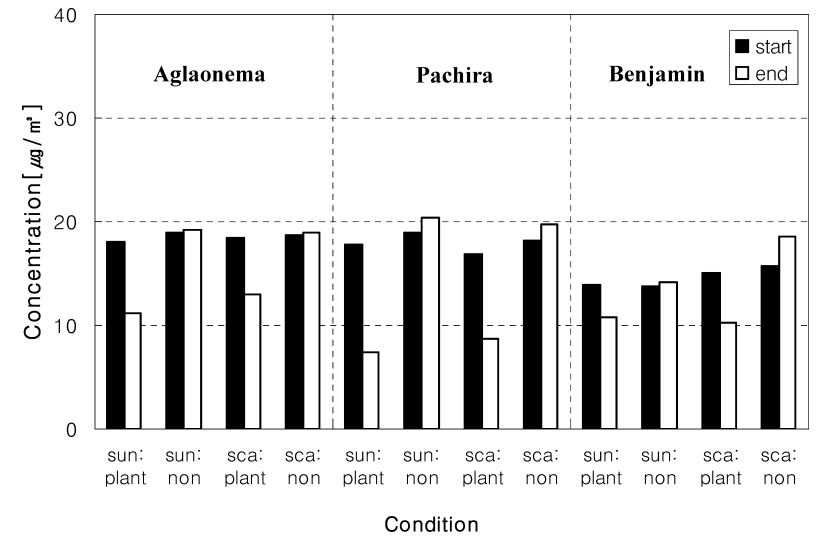

Fig. 10 Variation of Benzene concentration according to the positioning of plants.

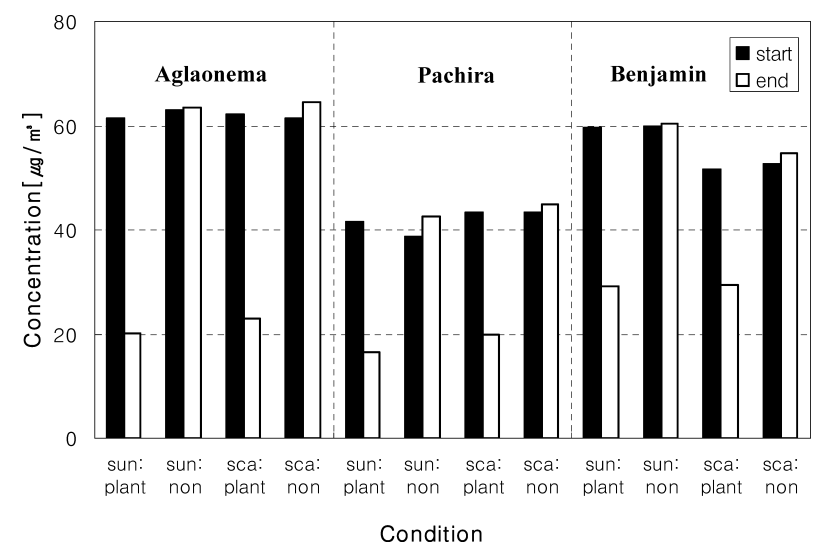

Fig. 11 Variation of Toluene according to the positioning of plants.

4) Xylene was most effective when Pachira was placed in a sunny area. The reduced amount of Xylene was in the priority order of Pachira, Aglaonema, and Ficus benjamiana. The variation of Xylene concentration is shown in Fig. 13.

5) Formaldehyde was most effective showing a reduction of $250.7 \mu \mathrm{g} / \mathrm{m}^{3}$ when Aglaonema was placed in a sunny area. Formaldehyde showed a lot of reduction of condensation in the presence of all plants, the effect being most prominent in a sunny area. The variation of Formaldehyde concentration is shown in Fig. 14.

\section{Discussion}

This study examined the condensation reduction effect of air pollutant materials after plants were set up in a room, and reached the following conclusions:

1) All air pollutants were reduced in condensation when plants were placed.

2) In this experiment of using different numbers of plants, the more planted, the more the reduction in pollutants. In particular, Formaldehyde and Toluene were greatly reduced. There was a tremendous effect on Toluene and Formaldehyde as a result of planting $10 \%$ of Aglaonema.

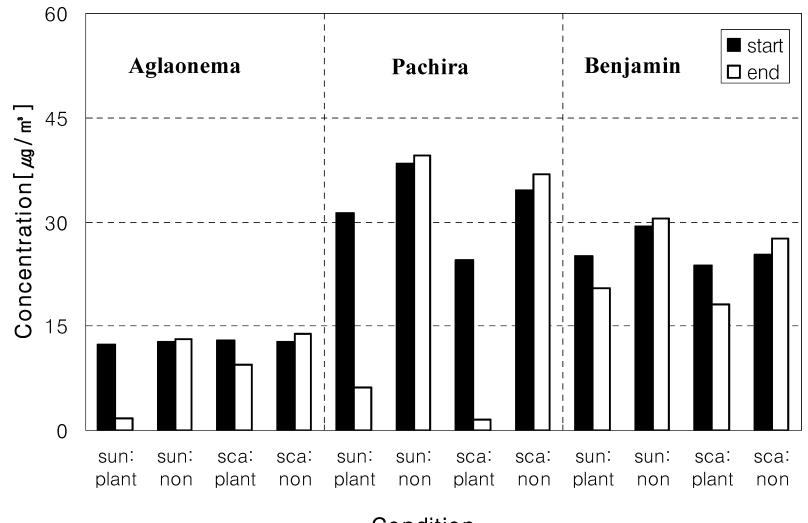

Condition

Fig. 12 Variation of Etylbenzene according to the positioning of plants.

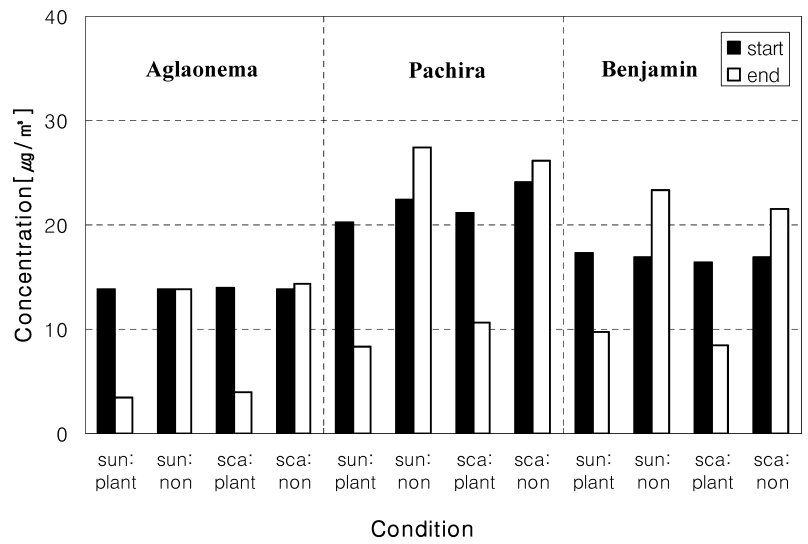

Fig. 13 Variation of Xylene according to the positioning of plants.

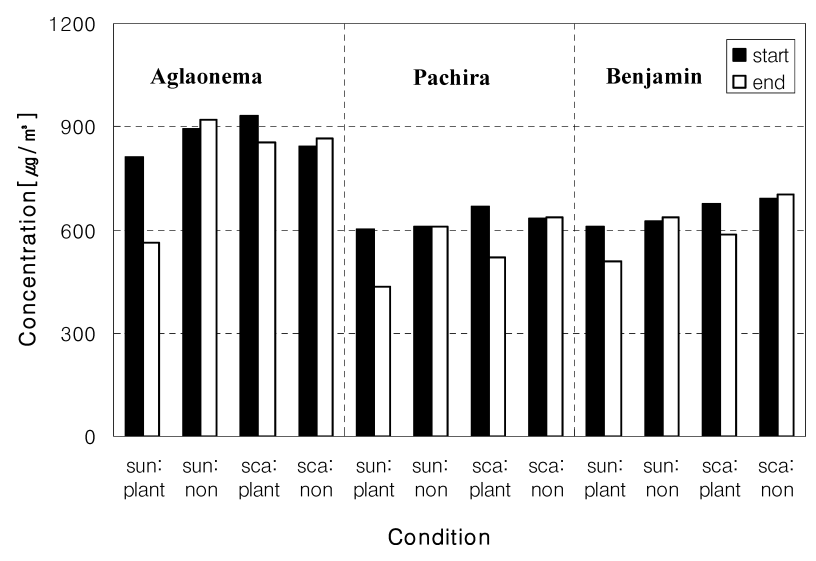

Fig. 14 Variation of Formaldehyde according to the positioning of plants.

3) In this experiment, condensation was much reduced when Aglaonema and Pachira were placed in a sunny area. There was great decrease in VOCs level after arrangement of Aglaonema in a place in the sun.

4) There was a great effect of planting Aglaonema among three other plants on the basis of the experiments of the 
amount of plants and position of plants.

Acknowledgements This study was partly supported by the Ministry of the Environment, Republic of Korea.

\section{References}

Cornejo JJ, Munoz FG, Ma CY, Stewart AJ (1999) Studies on the Decontamination of Air by Plants, Ecotoxicology

Hunter P, Oyama ST (2000) Control of Volatile Organic Compound Emission, John Wiley \& Sons Inc., New York

Owen SM, Harley P, Guenther A, Hewitt CN (2002) Light dependency of VOC emissions from selected Mediterranean plant species, ATMOSPHERIC ENVIRONMENT

NASA (2004) The Importance of Plants in Space, http:/www.nasa.gov/audience/forstudents/postsecondary/fea
tures/F_Importance_of_Plants_in_Space.html

NASA (2004) NASA Research Enhances Benefits Of Plant Experiments, http:/www. nasa. gov/home/hqnews/2004/jan/ HQ_04018_plant_expmts.html

This article was presented at the 8th International Congress of Physiological Anthropology, 2006 (ICPA 2006), in Kamakura, Japan.

Received: September 30, 2006

Accepted: December 25, 2006

Correspondence to: Jeong-Eun Song, M.S., Dept. of Architectural Engineering, Graduate School, Hanyang University, 17 Haengdang-dong Seongdong-ku, Seoul, Korea

Phone: + 82-2-2220-0313

Fax: +82-2-2296-5331

e-mail: jesong@hanyang.ac.kr 